\title{
Person-to-Person Electronic Funds Transfers: Recent Developments and Policy Issues
}

\author{
Oz Shy
}

\begin{abstract}
:
The paper investigates the reasons why person-to-person electronic funds transfers are still not very common in the United States compared with practices in many other countries. The paper also describes recent enhancements to online and mobile banking that provide account holders with low-cost interfaces to manage person-to-person electronic funds transfers via automated clearing house $(\mathrm{ACH})$. On the theoretical side, the paper characterizes the critical mass levels needed for payment instruments to become widely adopted. Given the Fed's long-term heavy involvement in check clearing, the paper concludes with policy discussions of whether intervention is needed.
\end{abstract}

Keywords: Automated clearing houses (ACH); Person-to-person Electronic Funds Transfers; Account-to-account transfers; Online Banking; Mobile banking.

\section{JEL Classifications: E42, G29, D14}

Oz Shy is a senior economist at the Federal Reserve Bank of Boston and a member of the Consumer Payments Research Center in the research department.

I thank Terri Bradford, Sean Carter, Dickson Chu, Paul Connolly, Marianne Crowe, Jean Fisher, Charles Fletcher, Fumiko Hayashi, Ben Levinger, Suzanne Lorant, Richard Oliver, Scott Schuh, Joanna Stavins, Bob Triest, Marianne Verdier, Mike Zabek, and Jeff Zhang for all their help and guidance.

This paper, which may be revised, is available on the web site of the Federal Reserve Bank of Boston at http://www.bos.frb.org/economic/ppdp/index.htm.

The views and opinions expressed in this paper are those of the author and do not necessarily represent the views of the Federal Reserve Bank of Boston or the Federal Reserve System.

version of: March 2, 2010 


\section{Introduction}

During the second half of 2009, several major commercial banks in the United States began introducing a new interface that enables account holders who use online and mobile phone banking to electronically transfer money from their own bank account to any other bank account within the United States and even, in some cases, internationally. In fact, Bank of America (the largest in terms of total U.S. deposits) announced this service in August 2009. ${ }^{1}$ The list of banks offering this interface includes PNC Financial Services, ING Direct, Bank of the West, and the Boeing Employees' Credit Union. This list is expected to grow during the first quarter of 2010 (see Javelin 2009). While it may be too early to tell whether these innovations signal a major change in attitude of commercial banks and the American consumer towards the way that money moves between accounts, these changes open up opportunities for individuals, consumers, and small businesses to substitute cash, checks, and payment cards with electronic funds transfers.

One of the goals of this paper is to identify the reasons why electronic funds transfers among households and small businesses are still not very common in the United States compared with practices in other countries. I briefly examine and compare the costs associated with the main noncash payment instruments, such as checks, credit and debit cards, and ACH-based electronic transfers ( $\mathrm{ACH}$ stands for automated clearing houses, described in Appendix A). International comparisons of the use of person-to-person electronic funds transfers are also provided.

Money transfers are generally characterized by the type of entities involved and the direction of transfer. The most common types are from: (i) person to person (P2P), (ii) person to business (P2B), (iii) business to person (B2P), and (iv) business to business (B2B). Adding local and federal governments, transfers are also made from (v) person to governments (P2G), (vi) governments to person (G2P), (vii) business to governments (B2G), and (viii) governments to business (G2B). Leaving governments aside, P2P transfers hardly exist in the United States. B2P

\footnotetext{
${ }^{1}$ See http://infocenter.bankofamerica.com/ic2/online-banking/transfer-funds-outside-bank/
} 
transfers are also rare except for salary direct deposits. P2P transfers are either cash based or accomplished by writing personal paper checks. Even large financial institutions and utility and phone companies that accept $\mathrm{ACH}$ payments from their customers, tend to reimburse their customers by mailing them paper checks. Many companies that pay salaries electronically via the $\mathrm{ACH}$ still do not use the $\mathrm{ACH}$ to reimburse their employees (say, for travel expenses). In most cases, companies reimburse their employees by sending them paper checks. The receiving party must then physically deposit or mail the paper check in order to get credit in her personal account.

This paper provides international evidence on the use of online P2P fund transfers. P2P electronic funds transfers dominate some European countries where checkbooks are not used by households. For example, it is very common for a schoolteacher in Germany to collect money for a certain school activity (such as an end-of-year class trip) via this system. The teacher simply provides parents with her own bank account information, and parents use their Web access to their bank account to transfer any amount of money at no cost to them, adding a note stating the student's name and the purpose of the transfer. Most bills in Germany (such as payments made to dentists, daycare centers, and landlords) are also paid via account-to-account electronic transfers because most people do not have a checkbook. Thus, in Germany, merchants and consumers view electronic transfers of this sort as the most practical and least costly alternative to cash and plastic card transactions (see Litan and Baily 2009).

This paper describes very recent developments in the United States that enable households to have access to low-cost interfaces for P2P funds transfers via their online banking and mobile devices. Because low-cost P2P transfers via online banking have not been available, in recent years some depositors have learned how to bypass this obstacle by making P2P transfers as if they were bill payments, but in most cases banks have mailed paper checks to the receiving parties, who could be landlords, dentists, and/or family members. Several papers, such as D'Silva (2009), predict that the availability of low-cost online P2P transfers is where the industry is heading, especially because domestic payments between individuals in the United States are currently estimated to be around \$2.9 trillion annually. 
This paper explores some theoretical frameworks that are frequently used to analyze the adoption of new payment instruments and explains why it is too early to predict whether online and mobile P2P (as well as P2B and B2P) will become the key payment instruments in the United States, as they are in some other countries. I also draw parallel with e-cash cards (electronic purse), which failed to become a major payment instrument in the United States. ${ }^{2}$

This paper also defines and characterizes the phenomenon of a critical mass of users, a phenomenon that triggers network (snowball) effects that enhance the adoption of a new technology-in this case, the adoption of a payment method by households and merchants. Using this framework, the paper addresses two main policy questions:

1. Given the Fed's long-term, heavy involvement in check clearing, should the Fed take any action to facilitate the development and adoption of P2P transfer technologies?

2. If the answer is yes, what are the possible means of intervention (if any)?

The major findings in this paper are:

1. The earlier heavy use of electronic P2P and P2B funds transfers in Europe than in the United States cannot be explained by earlier adoption of online banking or online bill payment in Europe. In fact, this paper shows that adoption patterns were very similar on the two continents.

2. Instead, this paper finds that the European lead in electronic P2P was a natural extension of the "old" Giro payment networks, which were accessible to all consumers via many European post offices and financial institutions (see Appendix B). In addition, more recent heavy involvement by the ECB and national central banks have also played a major role in transforming national electronic payment networks into international networks.

${ }^{2}$ Stored value cards have been successful in some closed networks, such as the military and some campuses. 
3. Given the Fed's heavy involvement in check clearing during the past 90 years and the federal government's continued involvement via the Check 21 Act of 2003, this paper suggests that it may be necessary to widen the gap between the fees charged by the Fed for check clearing and the fees charged for ACH transfers, in order to signal that paper check activities will eventually be replaced by online and mobile electronic payments. ${ }^{3}$ The Fed could also adopt other means of intervention, such as public education and promotions.

\section{P2P Transfer Technologies: Recent Developments}

This section describes recent and ongoing developments in P2P electronic funds transfers. All these technologies utilize the $\mathrm{ACH}$ (described in Appendix A) to transfer funds between bank accounts of the transacting parties, but they may differ in the type of information the transacting parties must disclose to each other in order to complete an electronic P2P transfer.

Electronic funds transfers via online banking require payers to input the bank account and routing numbers ${ }^{4}$ of the person or business to whom they wish to send money and permit them to add remarks, such as an invoice number or other reason for the transfer, if needed. The recipient of a transfer, say, a family member, a friend, or a dentist, should be able to read the credited amount and the reason for the credit transfer on her (online or paper) account statement. In the case of a P2B transfer, the payee should be able to associate the transfer with a payment for a specific service, corresponding to a specific bill. The above description characterizes how P2P and P2B transfers have generally been made in Europe for over a decade. (Appendix B describes the Giro system, which relies on this type of information exchange.) However, in the United States, some of the newly introduced methods described below attempt

\footnotetext{
${ }^{3}$ Other central banks have taken even more active roles. The U.K. Payments Council Board has agreed to set a target date of 31st October 2018 to close the central cheque clearing system (Telegraph, Dec. 16, 2009).

${ }^{4}$ A routing transit number (RTN), also known as the American Bankers Association (ABA) number, is a nine-digit bank code that appears on the bottom of checks to identify a financial institution in the United States. This code is also used by Federal Reserve Banks and the automated clearing house to process funds transfers.
} 
to bypass the exchange of bank account information between the parties. ${ }^{5}$ As it turns out, individuals in the United States are more reluctant than European consumers to exchange bank account information. The reason for this difference may have to do with the historical reasons on which this country was founded (desire for privacy, minimum information collection by authorities), large distances, and immigration, although all this seems to be changing now, given the amount of information people now share in social networks such as Myspace, Facebook, and LinkedIn.

Table 1 describes the types and direction of information needed to complete a payment transaction using various payment instruments. ${ }^{6}$

\begin{tabular}{l|llll} 
Payment Instrument & Direction & Payer & Payee & Information Type \\
\hline Paper check & Pull & Yes & No & Bank account details \\
Debit/Credit Card & Pull & Yes & No & Card number \\
Online Banking P2P & Push & No & Yes & Bank account details \\
Internet P2P & Push & Yes & Yes & E-mail address \\
Mobile Phone P2P & Push & Yes & Yes & Phone numbers
\end{tabular}

Table 1: Information exchange between transacting parties.

Table 1 demonstrates how information exchange might differ between the transacting parties for the purpose of completing P2P electronic transfers and some traditional payment instruments, such as paper checks and payment cards. The major difference is whether it is the payer who must reveal the information to the payee or the other way around. More precisely, online P2P transfers are "push"-initiated transactions, because they are initiated by the payer. Therefore, a P2P transfer via online banking requires the payee to reveal her bank account details (account and routing numbers) to the payer who initiates the transaction. In contrast, checks and cards are "pull"-initiated transactions, because the clearing process is initiated by

\footnotetext{
5 There are emerging models in other countries (particularly in Africa and Asia) where P2P payments are made using mobile phones that require only the person's phone number to be shared.

6 Table 1 focuses only on the differences in the type and direction of information exchange among payment instruments. Clearly, there are other differences, such as insurance from loss/theft, convenience, and payment guarantee in case of fraud or insufficient funds.
} 
the payee and not by the payer. In this case, the payee does not reveal any information to the payer when she deposits a check into her bank account. ${ }^{7}$

In order to address households' fear of disclosing information to transaction parties, it seems that the industry is evolving in two ways. First, some commercial banks, such as ING Direct (www.ingdirect.com), have already integrated P2P transfers into their online banking. Large banks, such as Wells Fargo, Capital One, and Citibank, offer similar P2P inter-bank transfers that are currently limited to interbank transfers of customers who hold the accounts involved in both the sending and the receiving bank or to transfers to others' accounts within the same bank. For transfers made outside the payers' bank, the payer must input the payee's account and bank routing numbers. The payee then receives a short message service (SMS) or e-mail message asking her to verify her account details and to agree to receive the transfer. Another option is that the sending bank makes two small trial deposits before the first transfer is made. It should be mentioned that many banks in the United States still do not offer even the limited P2P services described above.

The second type of $\mathrm{P} 2 \mathrm{P}$ transfer is targeted at individuals who for some reason do not want to disclose their bank account details, despite the fact that these numbers are printed on every paper check they write. This "masked" P2P transfer is accomplished by services that translate email addresses and/or mobile phone numbers into bank account and routing numbers. This is the guiding principle behind PayPal (www.paypal.com): it eliminates the need to exchange credit card information. Instead, users exchange only their PayPal account details. These technologies have been developed by companies like CashEdge (www.cashedge.com), Fiserv (www.fiserv.com), iPay (www.ipaytechnologies.com), and Obopay (www.obopay.com). PNC, Bank of the West, Boeing Employees' Credit Union, First Hawaiian Bank, and Patelco Credit Union have already signed agreements to implement P2P services. It should be noted that all these services utilize the $\mathrm{ACH}$ (described in Appendix A) to transfer the funds between the

7 UPIC (www.upic.com), offered by the EPN, replaces confidential bank account information with a pseudo-number in the transaction. 
commercial banks involved in the transactions, regardless of whether the payer initiates the transfer via a mobile device or via the Internet.

Finally, several (not necessarily independent) parties have conducted a few market surveys to measure consumers' willingness to use P2P funds transfers. In a 2009 survey of 850 consumers by CashEdge, 81 percent responded that they would use P2P if it were offered by their banks. Seventy-seven percent prefer that this service be provided by financial institutions rather than as nonbank services. Similar numbers were reported by Fiserv. Javelin (2009) reports that, in 2009, 38 million households in the United States transferred funds to different individuals online, and that this number is expected to grow to 58 million in 2014.

\section{Network Goods and Their Unpredictable Adoption Rates}

A payment instrument like P2P is a "network good," in which the utility of each user depends on the number of other users who adopt the same or a compatible payment instrument. ${ }^{8}$ The demand for network goods and services was first analyzed in Rohlfs (1974) in the context of consumer demand for telecommunication subscription services. As this section will demonstrate, this demand structure seems to fit perfectly the "market" for P2P electronic funds transfers, which is illustrated in Figure 1.

Figure 1 displays an inverse market demand curve (price as a function of number of users). The vertical axis measures the subscription fee for the service (which could also be zero, if the connection were offered for free). The horizontal axis measures the number of subscribers at a given fee, where each potential subscriber chooses whether or not to adopt this service (the technical term for this is "unit demand"). ${ }^{9}$ What is somewhat special about this curve is that it is upward sloping when the number of subscribers is small. This is because users are willing to pay a higher connection fee as the number of subscribers increases, and will not be willing to pay any fee at all if the expected number of other subscribers is zero.

\footnotetext{
8 See Shy 2001 and the references therein for definitions and classifications of network externalities.

9 In this discussion we use the terms "adoption," "use," and "subscription" interchangeably. Note that adoption does not always imply use of a payment instrument.
} 


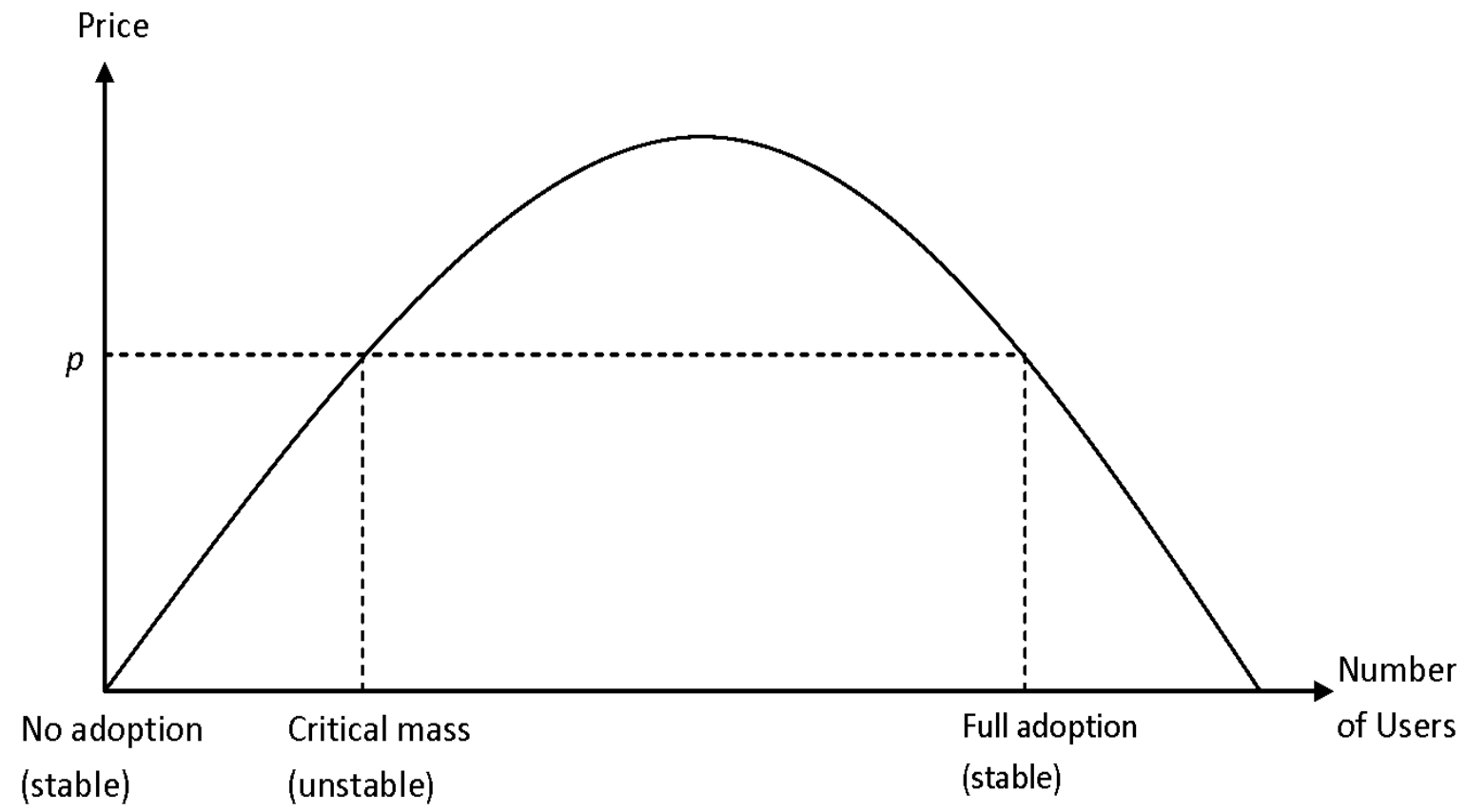

Figure 1: Demand for subscriptions to network services.

Figure 1 displays three possible adoption equilibria. Note that nonadoption (zero demand) is always an equilibrium even if $p=0$ (no charge), because in this "self-fulfilling" equilibrium all potential users expect no one to adopt this service and hence no one could benefit from this service.

The critical mass is defined as the minimum number of adoptions needed to make each adopter better off by adopting this payment instrument than by not adopting it. The critical mass equilibrium is often "unstable," because, at a given price $p$, a small deviation, say, an increase of one user, would make it beneficial for more new users to adopt the same payment instrument. In this case, a full-adoption stable equilibrium is reached. On the other hand, if, at a critical mass equilibrium, one user drops out of this service, all existing customers will follow and the market will settle on a nonadoption equilibrium.

For the more technical reader, a simple formulation of the inverse demand function plotted in Figure 1 can be expressed as $p=(N-n) \alpha n$, where $N$ is the maximum possible number of adopters (say, number of households) and $n$ is the actual number of adoptions at a give price 
p) $(0 \leq n \leq N)$. The parameter $\alpha>0$, to be estimated by the econometrician once data on fees and adoption rates become available, measures the degree of network effects (the utility from being able to send or receive funds to or from one additional P2P user). In this formulation, the equilibrium number of adoptions as a function of price is given by $n=\left[\alpha N \pm \sqrt{\alpha\left(\alpha N^{2}-4 p\right)}\right]$ / $2 \alpha$, where the smaller value of $n$ is the critical mass and the larger value of $n$ corresponds to full adoption; both are illustrated in Figure 1.

Economides and Himmelberg (1995) use a similar demand structure to calibrate for the parameters that measure consumers' valuation for network effects using aggregate time-series data on prices and quantities in the U.S. fax market. Using sales data from 1979 to 1992, they show that the surge in demand toward the end of the 1980s was not driven by outside shifts in consumer demand and price reductions as much as by the "feedback" effect induced both by past increases and by anticipated future increases in the size of the installed base.

The nonadoption equilibrium illustrated in Figure 1 demonstrates why it is especially hard to make predictions about the adoption of a new payment instrument. In the mid 1990s, various authors (including myself, see Shy and Tarkka 2002) predicted that e-cash cards (also known as electronic purses) would replace coins and notes by the first decade of the 21th century. This did not happen, despite intensive efforts by Visa, MasterCard, Chase, and Citibank, beginning in 1997 in the United States (see Van Hove 2001-2). E-cash has also failed to develop in other countries, with the exception of Hong Kong, which has had success with the Octopus card, and Singapore.

However, it should be pointed out that online P2P funds transfers and e-cash cards rely on conceptually very different networks of users. P2P transfers require that all users, whether they are individuals or businesses, use the same technology, which relies on online banking via the Internet or mobile devices. In contrast, the market for e-cash cards relies on two different technologies, one for for buyers and one for merchants. (Buyers need cards, whereas merchants must acquire card readers and connection services.) In the cards market, buyers will not acquire cards unless a sufficient number of merchants accept these cards, and the other way around: 
merchants will not invest in card readers unless a sufficient number of buyers possess these cards. ${ }^{10}$ Figure 2 illustrates the interaction between merchants and buyers in a market for e-cash cards (which is similar to the market for credit and debit cards).

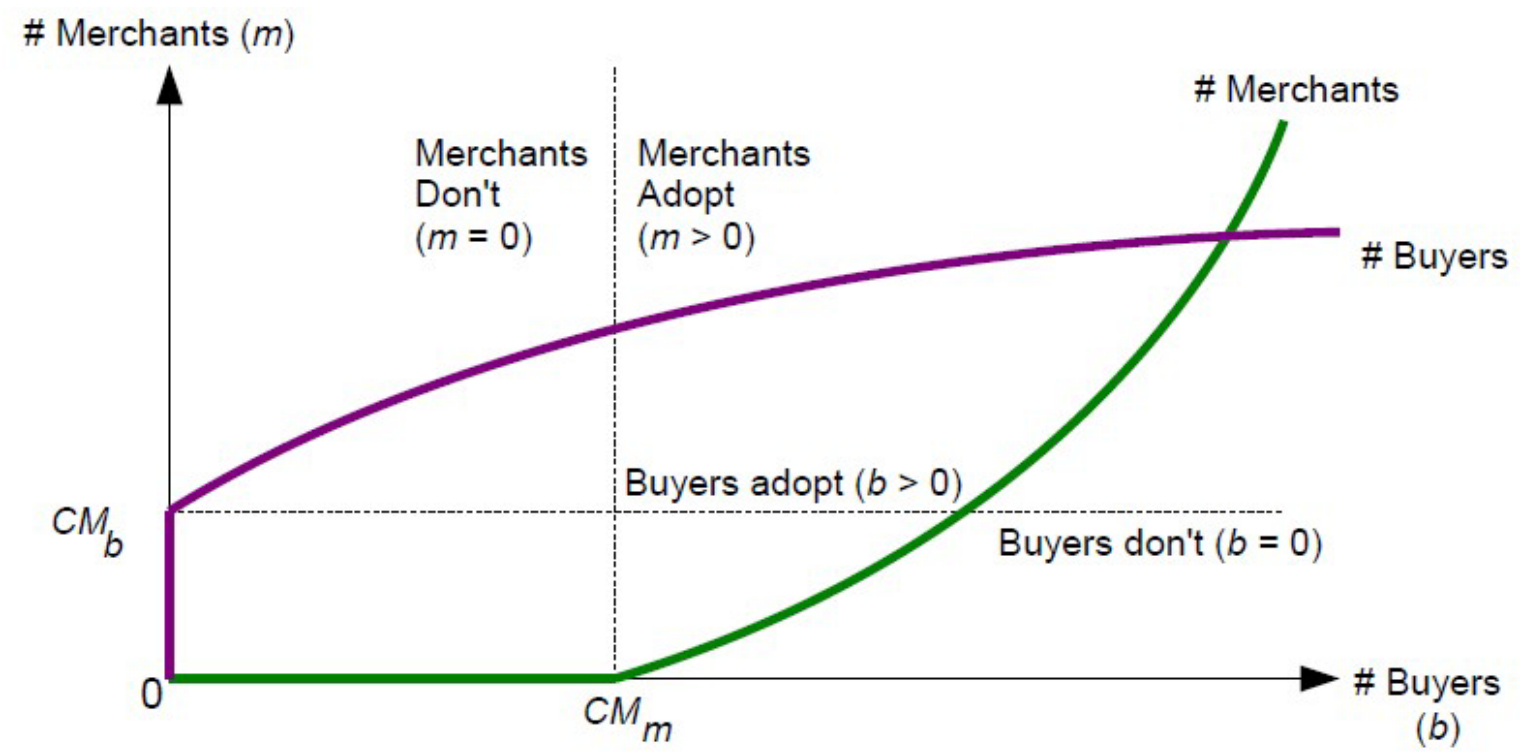

Figure 2: Buyers' and merchants' demand for card services.

Let $b$ and $m$ denote the number of buyers and merchants, respectively, who adopt a certain payment card. Figure 2 illustrates the "dual" externality in this market where merchants (green curve) do not adopt the card unless the number of buyers exceeds a certain critical mass, $C M_{m}$. Similarly, buyers (magenta curve) do not adopt the card unless the number of merchants accepting this card exceeds a critical mass $C M_{b}$. Mathematically, the adoption equations to be estimated are $b=\max \left\{0 ; \alpha_{b}\left(m-C M_{b}\right)^{\beta_{b}}\right\}$ and $m=\max \left\{0 ; \alpha_{m}\left(b-C M_{m}\right)^{\beta_{m}}\right\}$, where $\alpha_{b}, \alpha_{m}, \beta_{b}$, and $\beta_{m}$ are positive parameters to be estimated by the econometrician. Here, the number of buyers depends on the number of merchants and the other way around. Hence, market penetration of this card can be accomplished only after the adoption rates of both buyers and merchants exceed the other party's critical mass. Thus, the model illustrated in Figure 2

\footnotetext{
${ }^{10}$ Economists refer to this type of market as "two-sided." (See a literature survey in Rysman 2009.) For example, discotheques and dating bars often rely on having an equal number of males and females. Managers may consider setting a lower admission fee for males or females, depending on their relative abundance. This theory is heavily used to model the market for credit cards.
} 
may explain the failure of the e-cash cards to gain market share among the competing payment instruments.

Chakravorti (2000) lists some possible explanations for why, so far, stored-value cards (SVC) have not replaced other means of payment in the United States. Nowadays, the introduction of mobile payment technologies has reduced the need for these cards, because mobile devices can load (and unload) "cash" directly from the network without requiring an automated teller machine (ATM), while SVCs do require an ATM (or the Internet in the case of brand-name cards). In retrospect, mobile banking may gain advantage over SVC because most people now carry a phone that can be loaded over the network.

\section{International Comparisons}

As already noted and as explained in Humphrey, Pulley, and Vesala (2000), Knorr (2008), Litan and Baily (2009), and others, payments in the United States used to be dominated by paper checks, in contrast with European countries, which rely mainly on electronic funds transfers. Schuh and Stavins (forthcoming) document recent reductions in the use of checks in the United States. According to 2006 data for the United States, 16 percent of all noncash transactions were via $\mathrm{ACH}$, compared with 23 percent by credit card and 27 percent by debit card transactions, (Weiner 2008). The scope of use of $\mathrm{ACH}$ has also been on the rise beyond its traditional use for payroll deposits and government disbursements and now includes bill payments, check conversion, and online shopping, with the latter three uses reaching 33 percent of total $\mathrm{ACH}$ transactions. Appendix A provides data on the use of ACH by category.

Figure 3 compares the per-inhabitant yearly number of transactions associated with three noncash payment instruments: checks, credit transfers and direct debit (classified as $\mathrm{ACH}$ operations in this paper), and plastic cards, for a sample of 12 developed countries. ${ }^{11}$ The

\footnotetext{
${ }^{11}$ The Bank of International Settlements glossary (www.bis.org/publ/cpss00b.pdf) defines credit transfer as a payment order made for the purpose of placing funds at the disposal of the beneficiary. Both the payment instructions and the funds described therein move from the bank of the payer/originator to the bank of the beneficiary, possibly via several other banks as intermediaries and/or via more than one credit transfer system. Direct debit is a preauthorized debit on the payer's bank account initiated by the payee; examples include online bill payment and preauthorized transfers from individuals to financial institutions. I interpret credit transfers as all other electronic transfers similar to $\mathrm{ACH}, \mathrm{EPN}$, and Fedwire in the United States.
} 
differences in the number of transactions among countries may, at least partly, reflect differences in the use of cash as a means of payment (excluded from all charts in this paper). This may explain why Italy and Japan have a relatively small number of yearly transactions per inhabitant. Figure 3 demonstrates the infrequent use of electronic funds transfers and the frequent use of checks in the United States relative to other countries, and, in particular, relative to Germany and the Netherlands, where checks are rarely used. Most importantly, note that the composition of $\mathrm{ACH}$ operations in the United States differs substantially from that in most European countries, because online P2P has not been available in the United States until recently.

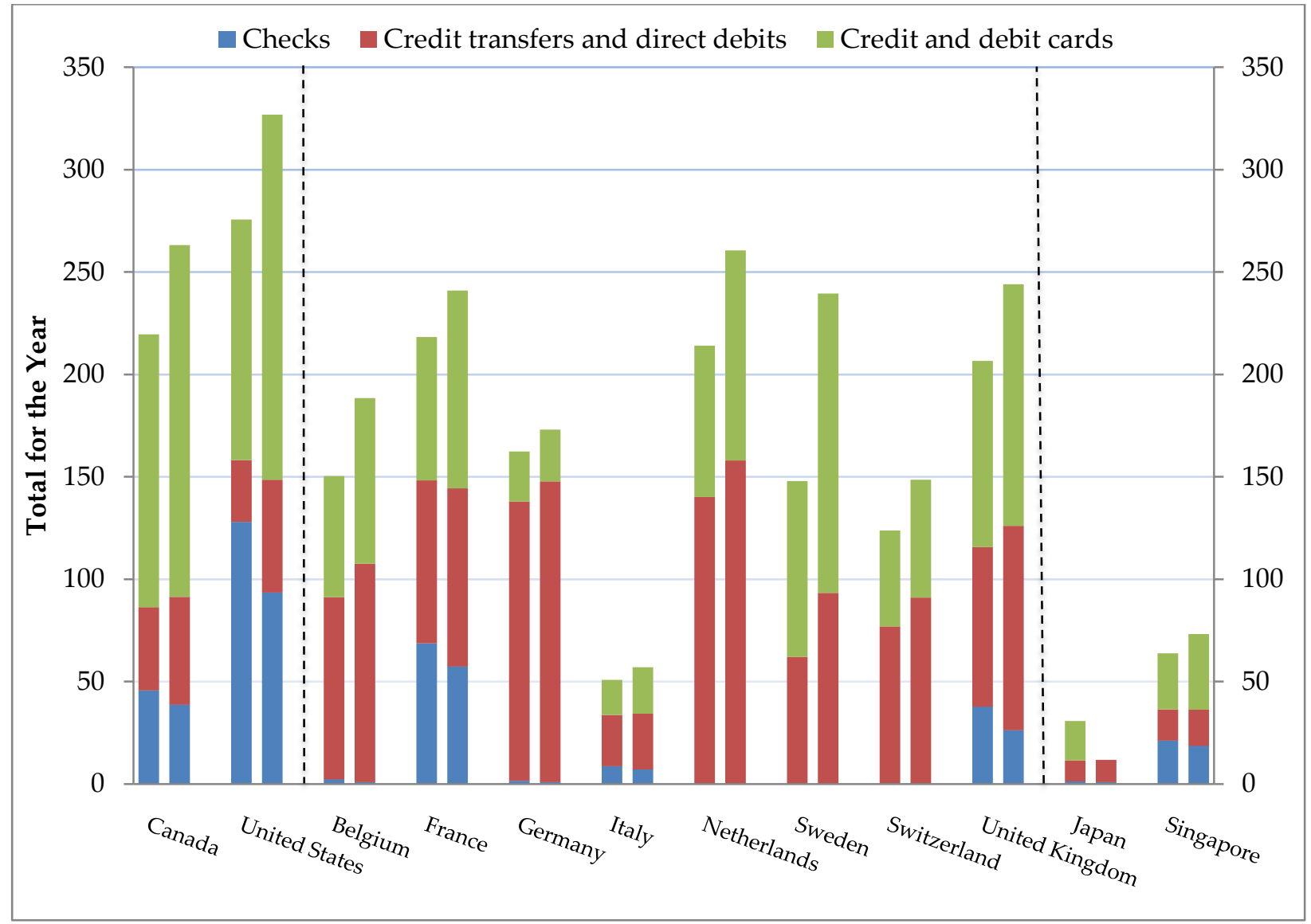

Figure 3: Use of payment instruments by nonbanks: Number of transactions per inhabitant (2003 and 2007).

Source: Bank of International Settlements. Note: Credit transfers and direct debits are classified as $\mathrm{ACH}$ operations. 
Figure 4 translates Figure 3 into percentage terms, and shows that in 2007 a representative individual in the United States paid with checks for 28.6 percent of her transactions. Only 16.8 percent of the total number of transactions were paid for via electronic transfers. The remaining 54.6 percent of transactions were paid by cards. In contrast, a representative German paid 84.7 percent of her transactions via electronic transfers, and only 0.58 percent of her transactions by check.

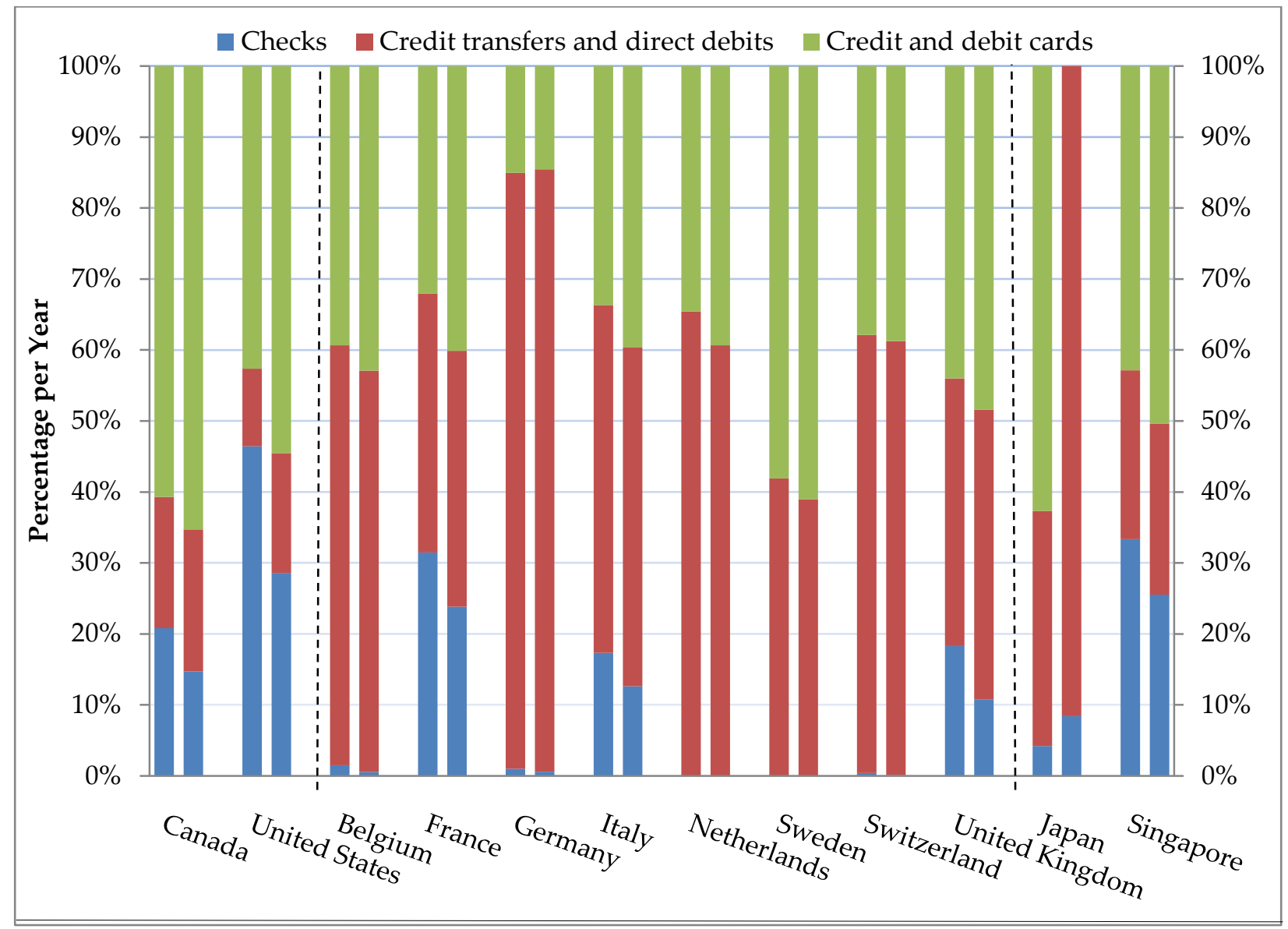

Figure 4: Shares of total transaction volume (2003 and 2007).

Source: Bank of International Settlements and author's calculations. 


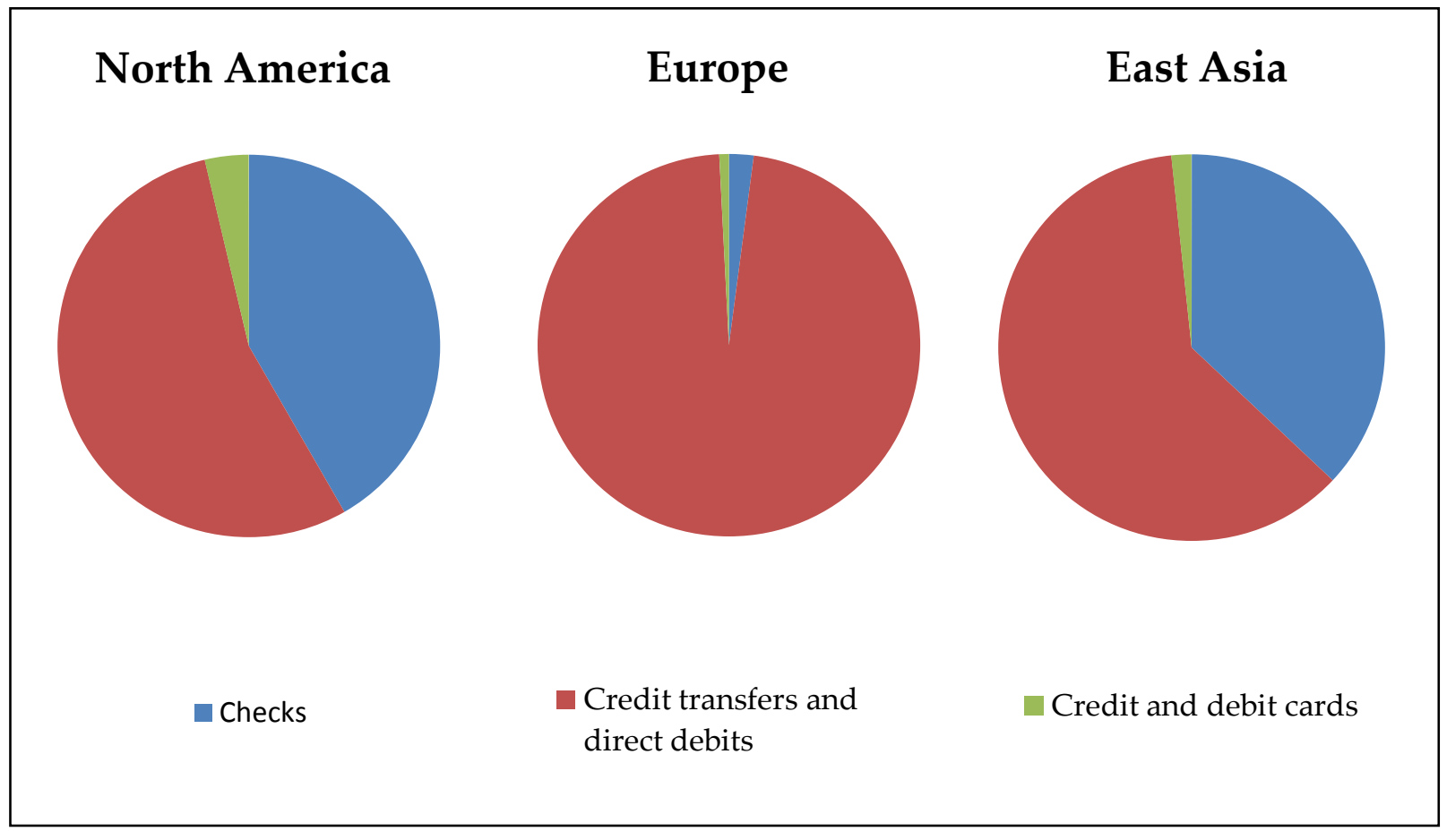

Figure 5: Shares of total transaction value by continent (2007).

Source: Bank of International Settlements and author's calculations.

Whereas Figures 3 and 4 focus on the yearly number of transactions per inhabitant, Figure 5 compares the percentage of each payment instrument by monetary value. The three continents (see dividing lines in Figures 3 and 4) are grouped into three pie charts in Figure 5 showing the low use of electronic transfers in North America relative to Europe and East Asia.

\section{Some Cost Considerations}

Economists generally distinguish between two types of costs: (i) social costs, which include production and service-delivery costs, user costs such as the value of time, and convenience, and (ii) private costs, which stem from the fees imposed on buyers, merchants, payment processors, and sometimes financial institutions. The first type of cost reflects "real" or "physical" costs (such as the use of electricity and labor), whereas the second type reflects only transfers among the agents that participate in the transaction. For assessing economic efficiency, only the first type of cost should matter. However, because electronic payments bear close-to- 
zero marginal costs (but have high fixed costs), it is sometimes difficult to distinguish between these two types of costs. Moreover, it is also difficult to compare costs, because each payment instrument has a different combination of fixed and marginal costs.

Regarding fixed costs, it should be pointed out that online funds transfers do not require buyers and merchants to invest in any new infrastructure as long as they are already connected to the Internet. ${ }^{12}$ As Litan and Baily (2009) point out, to use other instruments, such as checks, cards, or mobile devices, merchants must purchase special terminals in order to transmit check images or card information to their processors.

This section briefly discusses some (not very recent) cost study results that compare social and private costs of $\mathrm{ACH}$ transfers to other instruments. Recent studies focus mainly on cost comparisons of payment instruments that are used at shops' checkout counters and not on instruments that are used for online P2P funds transfers. Thus, future research is needed in order to collect and compare the costs of using various payment instruments outside the checkout counter.

Wells (1996) compares social and private costs of paper checks with ACH transfers and also provides interesting discussion of how the variety of costs associated with payments are calculated. Using 1993 data, Wells estimated that total private costs were $\$ 2.69-\$ 3.00$ for a paper check, and \$1.15-\$1.47 for an ACH payment. The corresponding total social costs were \$2.78\$3.09 and \$1.15-\$1.47. This indicates that in 1993 the per-transaction ACH costs were 40-50 percent lower than the costs of checks. All these costs have declined sharply since 1993, because of the decline in ICT (information and communications technology) capital prices, the introduction of Check 21, and also because the ACH network has been shown to operate under strong economies of scale (see Adams, Bauer, and Sickles 2004). Humphrey et al. (2003) show that, in 2000, retailers' costs per transaction were 36 cents for checks, 24 cents for ACH, and 34 cents for debit cards. They did not provide any data on banks' and consumer costs. Readers

\footnotetext{
${ }^{12}$ An April 2009 survey by the Pew Research Center's Internet \& American Life Project shows that 63 percent of adult Americans now have broadband Internet connections at home, a 15 percent increase from a year earlier. See www.pewinternet.org/Reports/2009/10-Home-Broadband-Adoption-2009.aspx .
} 
who wish to learn about the costs of using the various payment instruments in other countries are referred to Gresvik and Haare (2009) for Norway, and Bergman et al. (2007) for Sweden. In Norway, the per-transaction social cost was NOK 3.20 for electronic Giro and 17.08 for a paper Giro. ${ }^{13}$ The per-transaction social cost was NOK 2.62 for a direct debit, and 4.66 for direct credit. As a reference, the per-transaction social cost of paying cash (including ATM withdrawals) was NOK 12.26.

Adams, Bauer, and Sickles (2004) show that already in 2000 the Fed's marginal cost of an ACH transaction fell below 1 cent. In fact, there is a very simple way to estimate this cost. The 2008 FRB Annual Report states that the Reserve Banks recovered 101.5 percent of the total costs of their commercial ACH services in 2008. Reserve Banks' operating expenses, imputed costs, and imputed profits totaled $\$ 88.8$ million in that year, and they processed 10.0 billion commercial $\mathrm{ACH}$ transactions, which implies that the Fed's average cost for an $\mathrm{ACH}$ transaction in 2008 was 0.888 of a cent. This figure probably overstates the average cost because it may include imputed profits, addenda record charges, settlement fees, participation fees, electronic access fees, and some value-added services as well.

As mentioned earlier, banks in the United States have been slow to introduce P2P funds transfer services, so the first question that should be addressed is: what fees do banks pay for using the $\mathrm{ACH}$ ? This information is important because banks must take the first step to encourage the use of the $\mathrm{ACH}$ for P2P transfers of funds. As it turns out, the Fed charges banks in the range of 0.25-0.3 of a cent to originate an $\mathrm{ACH}$ and 0.25 of a cent to receive. In contrast, the Fed charges 5-16 cents for clearing a paper check and 0.7-1.5 cents for an electronic check. Note that these figures, which are publicly available from www.frbservices.org, refer to elementary services without any complication, such as rapid processing, returned payments, or other errors. The corresponding figures are higher if third-party processors are used. The total fees charged to banks are higher if third-party processors as well as Fed services are used.

\footnotetext{
${ }^{13}$ The exchange rate in January 2, 2009 was 6.87 NOK for 1 USD. Electronic Giro transfer is part of online banking. Paper Giro is intended for those who do not use online banking. It is accomplished at the branch, where the teller fills out a paper slip with the sender's and receiver's bank details. This information is then entered into the bank's computer.
} 
Finally, it should be mentioned that there is an additional potential saving to banks that introduce online P2P for transfers within the same bank. These electronic transfers can be done internally (commonly referred to as "on-us") without using the $\mathrm{ACH}$ (or any other network) at all. Therefore, larger banks make higher profits from "on-us" transfers than smaller banks do. D'Silva (2009) predicts that the share of on-us transactions will continue to grow because of consolidations and joint ventures, such as the joint venture between Wells Fargo and Bank of America, to process their ACH transactions directly between the banks and their clients.

\section{Online Banking and Online Bill Payments in the United States}

P2P funds transfers in the United States are implemented as an enhancement of online banking and mobile smartphone technologies. This section briefly describes the development of online banking in the United States; see also VanHoose (2009) and references therein. However, the reader may want to bear in mind that to some degree noncheck P2P transfers were possible even before households had access to the Internet (in Europe via the Giro network and in the United States via services like Western Union).

Online banking began on October 6, 1995, when Presidential Savings Bank offered its customers an online alternative to traditional brick and mortar banking (see www.presidential.com). This move in electronic customer convenience was quickly emulated by an Internet-only bank, Security First Network Bank, followed by other "brick and click" banks such as Wells Fargo, Bank One, and Chase Manhattan Bank. A survey by the American Bankers Association published in September 2009 shows that for the first time, more bank customers (25 percent) prefer to do their banking online over any other method (such as via an ATM or by visiting a branch). ${ }^{14}$

Online banking solutions can be classified as transactional or nontransactional. The latter include general bank information, branch locations, fees, account types, and interest rates. Transactional services include the opening of new accounts, funds transfers among accounts

\footnotetext{
14 See, http://www.aba.com/Press+Room/092109ConsumerSurveyPBM.htm
} 
(such as between savings and checking), electronic bill presentment and payments (EBPP), investment purchase and sale, loan applications, national and international transfers via Fedwire and SWIFT (not all banks), and the imminent ability to accomplish P2P funds transfers via the $\mathrm{ACH}$.

The historical development of online bill payment is highly relevant for this paper, because it may serve as a prediction of how fast households and small businesses can adapt to online P2P transfers before and after reaching the critical mass described in Section 3. Online bill payment allows consumers to manage and initiate bill payments electronically through a single portal. Roth (2008) reports that when banks first offered the service, consumers paid a monthly fee for a specific number of bill payments and an additional transaction fee for every bill payment beyond the designated limit. ${ }^{15}$ Alternatively, consumers compensated financial institutions by maintaining minimum balances in deposit accounts. Citibank began offering free online bill payment as early as 1997, but according to Roth (2008) it was Bank of America's 2002 announcement of the free service for new subscribers, supported by intense marketing and advertising, that kick-started the movement to offer free online bill payment. Bank of America's decision, announced in May 2002, led to a 14 percent rise in the number of active users of their online banking from the first quarter of 2002 to the second quarter of 2002: the number of users climbed to 3.8 million. Foster et al. (2009) report a 70.9 percent adoption rate of online banking and 52.6 percent adoption rate of online bill payment (roughly 125 million people ages 18 and older). This survey also found that 33.9 percent (roughly 81 million people) actually used online banking at least once in a typical month).

The above description of the adoption of online bill payment resembles the snowball effect associated with the adoption of any new payment instrument analyzed in Section 3. Given the experience that households have gained over the years since online bill payment was introduced, the adoption of $\mathrm{P} 2 \mathrm{P}$ as well as enhancements to $\mathrm{B} 2 \mathrm{P}$ and $\mathrm{P} 2 \mathrm{~B}$ could be much faster, if consumers were to find this service beneficial, as suggested by the surveys quoted in Section

\footnotetext{
15 Technically speaking, this "two-part tariff" fee structure is known to be the most profitable. See Shy (2008), Ch.5.
} 
2. In a sense, payment instruments can be viewed as "experience goods,"goods whose quality users cannot assess without first trying them. ${ }^{16}$

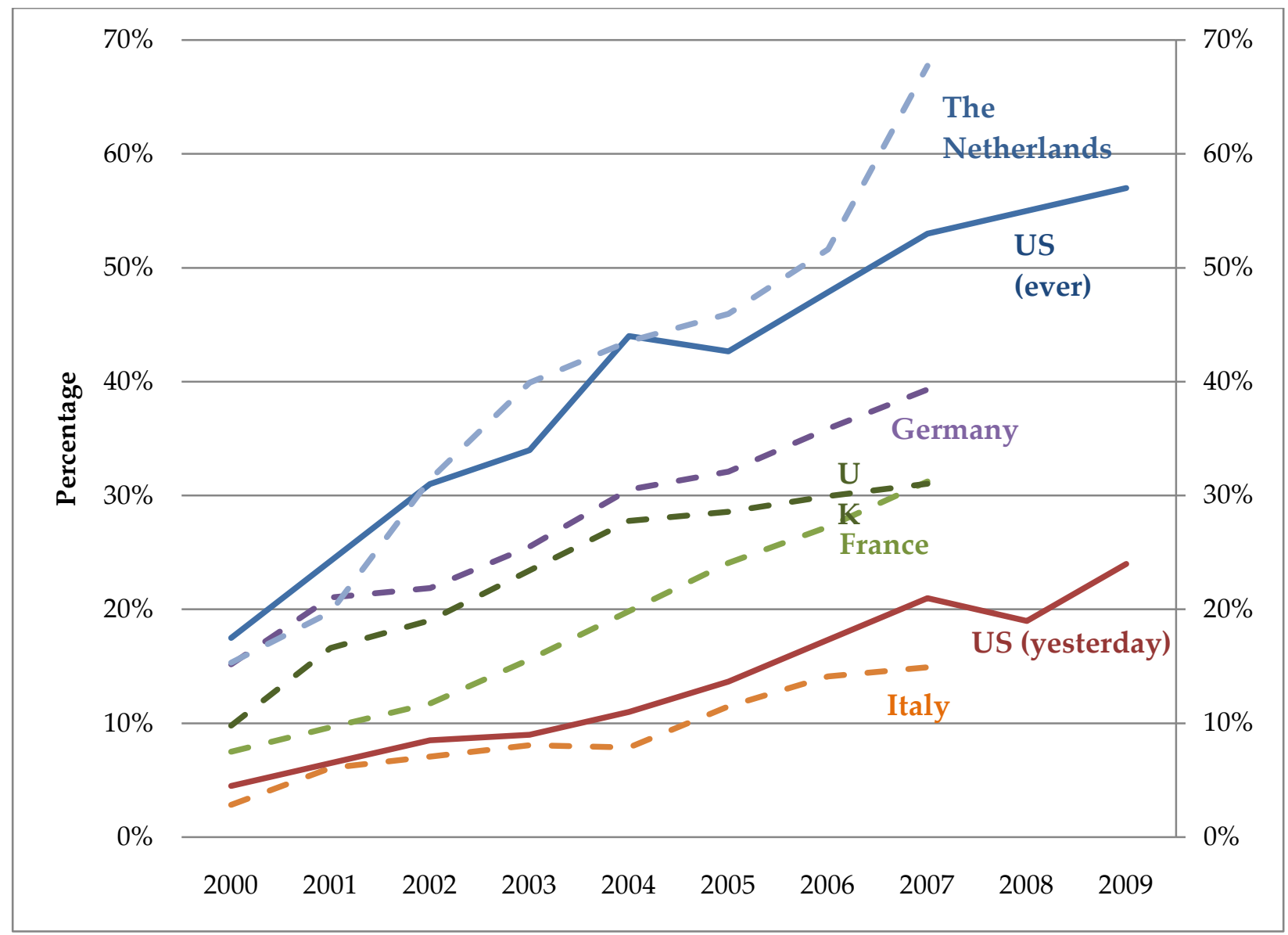

Figure 6: Online banking adoption rates in various countries.

Source: European data are from Forrester research. U.S. data are from the Pew Research Center's Internet and American Life Project.

A key question to ask at this point is whether the heavy use of online P2P transfers in Europe relative to its use in the United States stems from earlier adoption of any form of online banking. Figure 6 compares the development of online banking among six countries.

In Figure 6, the European respondents (dashed lines) answered a question asking whether they had used online banking in the past three months. Respondents in the United States were asked

\footnotetext{
16 The term "experience good" is heavily used in advertising models, in contrast with "search good,"a good whose
} quality can be observed before the time of purchase. See Nelson (1970). 
whether they had ever used online banking (solid blue line), and whether they had used it yesterday (solid red line). If we interpret three months as being between "ever" and "yesterday," we can conclude that there are no significant differences between these European countries and the United States. Therefore, Figure 6 suggests that the heavy use of P2P in Europe relative to the United States cannot be explained by any head start in online banking.

\section{Incentives}

In view of the recent developments in P2P payment technologies, a natural question that arises is why most commercial banks in the United States lacked sufficient incentives to offer low-cost P2P transfers via online banking at an earlier stage.

One explanation for the slow introduction of online P2P transfers could be that commercial banks fear that it may cut into their profits from other services, such as FedWire transfers as well as overdraft fees and float revenues generated from checks. However, because some consumers have figured out how to use online bill payment for P2P transfers (where consumers enter information online but banks send paper checks to payees), banks may now have sufficient incentives to introduce online P2P transfers in a more direct manner.

Paradoxically, a second possible explanation for the relatively slow introduction of online P2P via $\mathrm{ACH}$ transfers in the United States might be a result of the transition from paper check clearing to the use of image check clearing (commonly referred to as check truncation, or substitute checks), following the Check 21 Act of 2003. The use of digital check imaging has substantially reduced the cost of check clearing borne by banks and processing centers (Connolly 2007). In fact, the Fed charges banks 0.7-1.5 cents to clear an electronic check, whereas it charges 5-16 cents to clear a paper check (all fees are listed on www.frbservices.org). This difference in cost is expected to rise even further in 2010, when the Fed consolidates all paper clearing facilities into one center in Cleveland (from 45 centers in 2003), where all paper checks will be shipped. In addition, electronic checks clear much faster than paper checks. The 2007 Federal Reserve Payments Study reports that about 40 percent of all interbank checks involved replacement of the original paper check with electronic payment information during the 
collection process. As of December 2009, 98 percent of all check deposits are received electronically via Check 21. Check 21 has also decreased merchants' incentive to accept electronic payments, because it enables "remote deposit," whereby depositing merchants can capture front and rear images of checks along with their respective MICR (magnetic ink character recognition) data. The data are then uploaded to the merchant's depositing institution and the merchant's account is then credited. Remote deposit therefore precludes the need for merchants and other large depositors to travel to the bank (or branch) to physically make a deposit. Thus, some features of Check 21 have reduced the incentives of merchants to resist checks, and may also have influenced the banking industry against offering low-cost P2B and P2P electronic transfers via online banking.

On the household side, current bank pricing practices to consumers do not incent the consumer to stop writing checks, as a P2P solution. Check 21 accelerated the clearing of checks, so the banks are less troubled by their use. Thus, banks continue to offer free checking services, thereby insulating households from the higher costs of transacting by check relative to $\mathrm{ACH}$ based transactions.In fact, some countries have gone in the opposite direction from that taken by the U.S. Fed with respect to their check clearing policies. England has announced that it will be closing its central check clearing center in October 2018 (eight years from now). Canada (where the banking industry is much more concentrated than in the U.S.) has not adopted Check 21-type regulation, but instead has managed to reduce the volume of paper checks by inducing consumers to use electronic means. Canadian consumers do not gain check-clearing "float" on their checks, because checks are charged to check writers on the date they are written, regardless of when the checks are actually presented.

So, why do banks and processors now find it profitable to introduce P2P transfer solutions? One explanation for this change may be the recognition that there is high demand for online funds transfer and that if banks do not offer it, other companies will. In fact, with over 93 million active accounts and growing, PayPal now offers free transfer of funds for noncommercial purposes. Since September 2009, PayPal has also allowed parents to open PayPal accounts for children ages 13 and up, which parents can access via their own online accounts to costlessly 
move money in and out of these accounts and which allow children to obtain a brand-name debit card to use with their accounts.

Another explanation may be that banks are now beginning to realize that even if no profits can be made from P2P funds transfers, profits may be generated by providing other, complementary services. For example, Roth (2008) describes how banks can enhance profits by providing expedited bill payment services. Another stream of revenue could come from overdraft fees on P2P payments, similar to overdraft fees on debit card transactions. Note that eventually lawmakers and regulators may want to keep an eye on and possibly regulate pricing and competition in this market, given the situation with other bank fees.

Section 6 described online banking and argued that consumer experience with online banking bill payments (OBBP) is likely to expedite the adoption of online P2P funds transfers. This is because both OBBP and P2P transfers require consumers to input some personal information and to make almost the same number of "clicks" on their banks' Web site. But P2P and OBBP have other similarities. Apparently, some customers of major banks have learned how to use OBBP to send money to other people. All that consumers need do is input the name and address of the receipient into their OBBP, and then the bank usually sends a paper check to the recipient at no cost to the sender. ${ }^{17}$ Ironically, OBBP was designed to shift consumers and merchants from paper to digital transactions, but the use of OBBP for the purpose of P2P money transfers reflects a shift from digital back to paper check transactions-a shift that would increase banks' costs of operating OBBP. Perhaps banks' detection of this practice has motivated them to provide P2P services directly.

\section{Policy Implications}

Lacker and Weinberg (1998) and Lacker et al. (1999) analyze the historical role of the Fed's involvement in check clearing and its impact on the entire payment industry in the United States. More recently, the U.S. government echoed this involvement by enacting Check 21,

\footnotetext{
17 The main reason that OBBP results in checks being sent is that the standards for interfacing ACH formats with company accounts receivable systems are still not well developed.
} 
which supports electronic check clearing via the use of substitute checks. In addition, the Fed has been clearing more than 50 percent of $\mathrm{ACH}$ transactions over the years and has been helping small banks connect to the $\mathrm{ACH}$ (currently, 48 percent are cleared via the privately owned EPN network). Thus, it would not be unusual or inappropriate for the Fed to advise banks on the advantages of moving the payment industry towards the use of electronic P2P and other derived applications for $\mathrm{B} 2 \mathrm{P}$ and $\mathrm{P} 2 \mathrm{~B}$, as well as towards heavier use of $\mathrm{B} 2 \mathrm{~B}$ electronic transfers.

In this section I address the following difficult questions:

1. Given the Fed's long-term heavy involvement in check clearing, should the Fed take any action to facilitate the development of P2P transfer technologies?

2. If the answer is yes, what are the possible means of intervention (if any)?

\subsection{Should the Fed Intervene?}

P2P electronic transfers are not new. During 1999-2001, over 10 P2P service providers emerged, including Citibanks's C2it, Yahoo PayDirect, X.com, PayMe, and PayPal, which turned out to be the only successful survival. Bradford (2001) and Kuttner and McAndrews (2001) describe very early introductions of $\mathrm{P} 2 \mathrm{P}$ services by nonfinancial institutions as addressing the needs of participants in online auctions and for family transfers. With the exception of PayPal, P2P has not developed over the years.

This slow adoption may have been influenced, to some extent, by a lack of involvement and endorsement by the Fed. It should be pointed out that inaction is also a policy, simply because people tend to interpret inaction as endorsement of prevailing technologies. Although over the past five years the Fed has tried to get the industry to support same day $\mathrm{ACH}$, the lack of more "visible" involvement or at least endorsement of online P2P funds transfers via the ACH may have signaled to banks and households that checks (paper and electronic) will continue to serve as the main payment instrument for P2P transfer purposes. Appendix B describes the heavy 
involvement of the European Central Bank (ECB) in creating the TARGET and SEPA transfer networks, as well as the European Commission's regulatory involvement in the debit card system. (See also Humphrey, Kim, and Vale (2001) for the Norwegian case.) In the United States, however, the Fed has chosen to take a passive role.

Figure 7 illustrates one method of conducting a cost-benefit analysis of a new payment instrument, based on the demand for network services analyzed in Section 3 and Figure 1. ${ }^{18}$

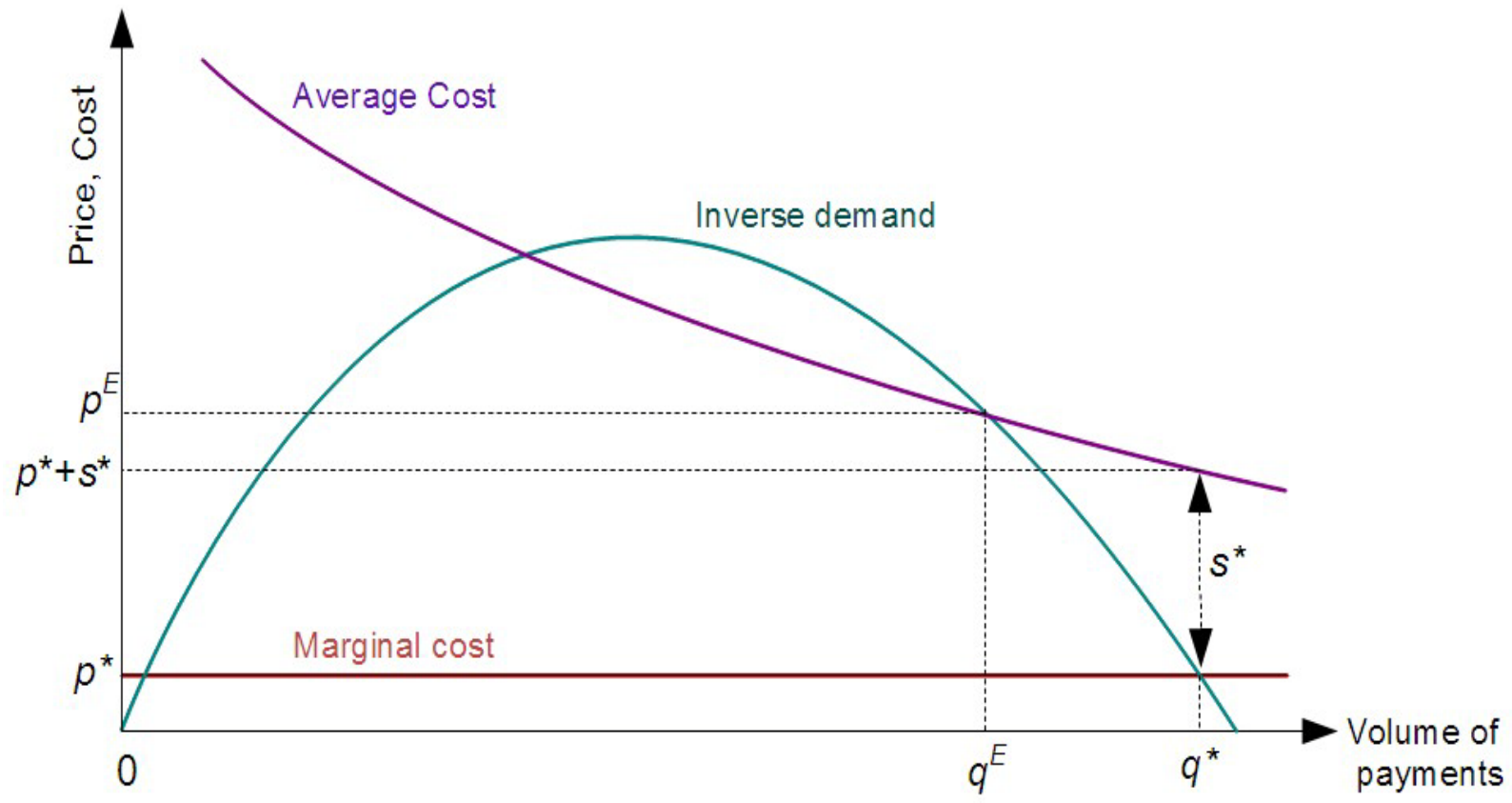

Figure 7: Cost-benefit analysis of a new payment instrument.

As Figure 7 shows, the introduction of a new payment instrument is socially beneficial if the average cost function intersects the demand function. It is not socially beneficial if the average cost curve lies completely above the inverse demand function. This is because the inverse demand curve reflects willingness to pay, and if it exceeds unit cost, it must be beneficial.

\footnotetext{
${ }_{18}$ Note that the average cost does not have a minimum and converges to marginal cost at high service levels. This type of average cost function is commonly observed in communication services and software industries and results from having a relatively high fixed construction/development cost and constant marginal cost. Formally, let total cost as a function of service volume be characterized by $T C(q)=F+c q$, where $F$ is the fixed cost and $c$ is the marginal cost (cost of increasing service volume by one unit). Then, the corresponding average cost function is $C(q)=F / q+c$ , which always declines with service volume and converges to marginal cost.
} 
The P2P payment fee $p^{E}$ and the corresponding volume of payments $q^{E}$ reflect an equilibrium at which the private sector breaks even, in which case no outside intervention is needed. A slightly higher fee $p>p^{E}$ yields strictly positive profit to the private sector. However, in the example given in Figure 7, the socially optimal volume of payments is $q^{*}$ which exceeds $q^{E}$. To achieve this volume, each payment should be given a subsidy $s^{*}$. Under this subsidy, the customer pays a fee $p^{*}$ and therefore makes $q^{*}$ payments. The payment service providers receive a subsidy-inclusive fee $p^{*}+s^{*}$ and break even. Note that this type of subsidy is commonly observed in public transportation, in which the average cost also exceeds marginal cost at all service levels as a result of economies of scale.

Although a subsidy may increase social welfare, it is not mandatory here because the private sector can "survive" by setting the higher price $p^{E}$. However, the problem in this market stems from the fact that most banks now provide "free" checking, and checks are considered to be substitutes for electronic P2P transfers in the United States. Had consumers faced the true cost of using checks, electronic P2P would probably have been able to gain market share and break even without any intervention on the part of the Fed, as demonstrated in Figure 7. Competition among banks prevents them from passing on the cost of handling checks to consumers, and this may slow the switch from checks to electronic P2P. Therefore, any discussion of whether the Fed should intervene must take into account how banks and the Fed affect the pricing of all other payment instruments and should also consider other means of intervention, such as public education and promotions.

The above analysis demonstrates that in order to determine whether the Fed should intervene, we must have reliable data on cost and demand. Unlike cost variables, which can be estimated, demand data (willingness to pay as a function of the number of users) are still not available and cannot be estimated until P2P transfers become widely used. At this point, the only available demand data come from a few surveys where individuals are asked, "How much are you willing to pay to transfer funds from your bank account to another account via online banking or your mobile phone?" This scattered information does not provide a sufficient number of data points to make a meaningful estimation of the demand illustrated in Figure 7. 
This paper does not address the more fundamental question of why ACH services should be provided by central banks rather than by the private sector or other government agencies. Some answers to this question have already been given in Weiner (2008) and Schreft (2007). The arguments they raise for the Fed's involvement include economies of scale and scope, reducing the risk of identity theft and providing safety mechanisms, and correcting market failures that generate underprovision of payment services. Their last argument should also be applicable to the currently observed underprovision of online P2P funds transfers. Looking outside the United States reveals that the ECB has been pushing P2P transfers by sponsoring its TARGET and more recently the SEPA projects. If the Fed decides to follow the ECB example, Lacker and Weinberg (1998) propose several methods to evaluate a new payment instrument. Stavins (1997) provides a good example of such investigations by estimating the social costs and benefits of introducing electronic check presentments to replace paper check clearing.

I conclude the discussion on whether the Fed should intervene by addressing the often neglected question of how the introduction of P2P online transfers would impact the payment industry as a whole, and the credit card industry in particular. In recent years, many lawsuits have been filed against card associations with respect to their coordination of interchange fees and the implementation of the no-surcharge rule, which prohibits merchants from openly transferring their fees to card users. Economic theory tells us that the simplest solution to these kinds of disputes is to introduce more competition into the payment industry. It seems that widespread use of online transfers would increase competition and this would eventually reduce the fees imposed by card issuers and card acquirers.

\subsection{Possible Means of Intervention}

The recent developments in P2P technologies described in Section 2 involve projects comanaged by banks and nonbank firms. For this reason, it is far from straightforward to determine how the Fed could help to enhance the adoption of online and mobile P2P funds transfer technologies. The following discussion suggests a few policy directions the Fed could take that might facilitate and accelerate the transition to online P2P funds transfers. 
Even if the Fed decides to influence the pace of adoption of online P2P, there remains the question of whether the Fed has the means to get involved and which form of intervention is most effective. These means may involve education and public announcements. The following discussion focuses only on the possible use of differential pricing. For example, would it make a difference if the Fed lowered the fees it charges commercial banks for clearing $\mathrm{ACH}$ transactions? Note that in order to maintain competition with the private sector (such as the EPN), the Fed may not be allowed to subsidize payment services, because, following the Depository Institutions Deregulation and Monetary Control Act of 1980, the Fed must recover the costs of providing these services over the long run. More precisely, following this act, the Fed has adopted the following principles: ${ }^{19}$

Over the long run, fees shall be established on the basis of all direct and indirect costs actually incurred in providing the Federal Reserve services priced, including interest on items credited prior to actual collection, overhead, and an allocation of imputed costs that takes into account the taxes that would have been paid and the return on capital that would have been provided had the services been furnished by a private business firm, except that the pricing principles shall give due regard to competitive factors and the provision of an adequate level of such services nationwide.

The interpretation of "long run" may allow latitude in the "short run" for the Fed to cut the fees on ACH transfers. In fact, the Fed has also adopted the following principle:

The structure of fees and service arrangements may be designed both to improve the efficient utilization of Federal Reserve services and to reflect desirable longer-run improvements in the nation's payment system. Public comment will be requested when changes in fees and service arrangements are proposed that would have significant longer-run effects on the nation's payment system.

One interpretation of the above quotations is that there are circumstances under which the Fed can deviate from strict cost-based fees if it does not damage competition with the private sector and when it intends "to reflect desirable longer-run improvements in the nation's payment system." The improvement in social welfare from the shift to online P2P transfers would come mainly from a reduction in the amount of labor needed to handle cash, check imaging, and

\footnotetext{
${ }^{19}$ See http://www.federalreserve.gov/paymentsystems/pfs_principles.htm
} 
paper checks. In general, economic theory tells us that deviation from cost-based pricing may be justified in the presence of consumption externalities. In the particular case of adopting a new payment instrument, there are strong adoption externalities in which the benefit derived by each consumer from using a payment instrument increases monotonically with the total number of other consumers using the same instrument (see Section 3 for the formal analysis). Note that the deviation from cost-based pricing can no longer be justified once the "snowball" effect starts generating high adoption rates.

There are three ways by which differential pricing could be introduced by the Fed without creating a significant deficit in the short run:

1. Initially giving overall $\mathrm{ACH}$ discounts to institutions that adopt online $\mathrm{P} 2 \mathrm{P}$ funds transfer, with the hope that the increase in volume will offset the reduction in fees.

2. Raising the fees on other Fed services (such as check clearing), while reducing the fee for $\mathrm{ACH}$ transactions.

3. Raising the fees on other Fed services (such as check clearing), while leaving the fee for $\mathrm{ACH}$ transactions unchanged.

The first two methods are somewhat problematic because they may end up diverting transactions from the competing EPN network to the Fed $\mathrm{ACH}$ network. ${ }^{20}$ In this respect, the third method is less problematic because it would maintain competition in the ACH market, and in addition, it would increase the size of the $\mathrm{ACH}$ market by reducing the volume of check clearing.

To bring in some numbers from Section 5, the Fed charges banks in the range of 0.25-0.3 of a cent for clearing a "standard" send or receive $\mathrm{ACH}$ transfer, whereas the average cost of an $\mathrm{ACH}$ transfer has been found to be much larger. There are other, nonstandard types of $\mathrm{ACH}$

20 This would not cause a problem if the EPN could match the Fed's reduced fees. However, if EPN lost market share, this would result in increased market concentration. 
transactions that are charged higher fees, and this may partly explain the gap between average and marginal costs. These computations hint that the Fed is already charging close to the marginal cost for clearing $\mathrm{ACH}$ transactions. Whether or not these figures are correct, even a total elimination of $\mathrm{ACH}$ fees would not affect individuals' demand, because it would result in a fee reduction of less than one cent per transaction. Recall that the $\mathrm{ACH}$ fee is only part of the cost of a P2P transaction.

The above discussion hints that option 3 above may be the only feasible way for the Fed to accelerate the adoption of P2P transfer services. Raising the fees on check clearing may have two effects. First, if banks pass these fees on to consumers, consumers themselves may seek alternative solutions to writing paper checks. At this point in time, banks are subsidizing check use for almost all account holders. Raising the fees on check clearing may convince banks to change this strategy and to charge consumers the full cost of using paper checks. This change may receive fresh consideration in response to the new rules against overdraft fees, which are leading banks to seek alternative revenue sources. Second, if banks choose not to pass check fees on to consumers, banks themselves will seek cost-cutting alternatives, and online P2P seems the least costly solution. As mentioned above, any discussion of Fed intervention must involve the pricing of all payment instruments that compete with electronic P2P.

\subsection{Long-Run Policy}

Humphrey, Pulley, and Vesala (2000) suggested that nonbank firms that wish to supply payment services in competition with banks need direct access to Federal Reserve payment services. They argue that direct access to the $\mathrm{ACH}$ by nonbanks would remove the monopoly access banks now have to low-cost check processing, $\mathrm{ACH}$, and bank reserve account transfer and settlement services, and would permit greater competition in the provision of payment services to the general public. Such suppliers would be freer to provide more efficient electronic payment arrangements where it is profitable to do so. This would enable payment firms such as PayPal to provide service without having to go through banks to initiate $\mathrm{ACH}$ operations. In turn, commercial banks would have stronger incentives to compete with nonbanks by 
introducing low-cost P2P platforms. Note that even today the Fed $\mathrm{ACH}$ network has sufficient excess capacity to accommodate all new services. ${ }^{21}$

Although extending access to the Fed ACH by nonbanks may be appealing, establishing precise criteria as to who may and who may not connect directly to the $\mathrm{ACH}$ would be a very difficult task for the Fed, for two reasons:22

1. Currently, many financial institutions that access the Fed $\mathrm{ACH}$ have accounts with the Fed, making bookkeeping fairly simple (debit one FI and credit another). Nonfinancial institutions cannot open their own accounts with the Fed and therefore cannot maintain a balance to avoid a situation in which the Fed might lose money as a result of a transfer.

2. Direct access to the $\mathrm{ACH}$ means having the ability to initiate $\mathrm{ACH}$ entries, and this may invite fraud. Of course, similar risks prevail in credit card networks and could be overcome if, for example, the Fed would require all parties that initiate $\mathrm{ACH}$ transactions to prefund their transactions.

A natural question arising from the Humphrey, Pulley, and Vesala (2000) proposal is whether nonbanks would have anything to gain from direct access to the $\mathrm{ACH}$ if they were required to maintain an account with the Fed. To take an example, PayPal transfers money among PayPal members, but PayPal is not a bank and therefore must store all its funds with commercial banks. If PayPal were ever to become a bank, it would be subject to a totally different type of regulation, which it may want to avoid. But if PayPal were allowed direct access to the $\mathrm{ACH}$ by depositing sufficient funds as collateral, it would not need to be regulated, and it could remain registered as a "money transmitting" company rather than as a bank.

\footnotetext{
${ }^{21}$ The actual capacity is hard to estimate, but the Fed does conduct capacity tests in order to be able to accommodate traffic in case of a disruption of other ACH providers.

22 Technically speaking, there are two aspects to direct access: connectivity and settlement. The first already exists if a bank will sponsor it. Settlement, on the other hand, is not likely in the near future for risk management reasons.
} 
Humphrey, Pulley, and Vesala (2000) also advocate legislation to allow retailers the option to apply discounts or surcharges to payers, depending on which payment instrument they use (for example, by disallowing the no-surcharge rule on credit cards). This would permit payees to directly recoup the high cost of accepting credit cards and would reduce the cross-subsidy that now exists among payment instruments. With proper surcharges according to cost, consumers would be more likely to choose online P2B transfers over the online use of credit cards. This suggestion is not new. In fact, in many parts of the world, antitrust authorities have declared the well-known "no-surcharge-rule" imposed by card organizations to be a violation of antitrust law (known outside the United States as "competition law"). This rule remains legal in the United States.

\section{Concluding Remarks}

Gowrisankaran and Stavins (2004) have investigated empirically the degree to which the adoption of $\mathrm{ACH}$ by banks exhibits network effects. Clearly, this is only one side of the story, because transactions among consumers and small businesses may exhibit even stronger network effects. Once a consumer receives some money from a friend via $\mathrm{ACH}$, the consumer is likely to investigate whether she can also use this system to transfer money herself. If this consumer happens to run a small business, she will probably wonder why her business is not using the same means of payment to collect fees from her clients. The point is that the availability of direct account-to-account online transfers may (or may not) change the way small businesses pay and receive payments, because both merchants and buyers may become more comfortable with B2P and P2B online and mobile transfers. Currently, 74 percent of B2B payments are still originated by paper checks, and 47 percent of these checks are written by small and mid-size businesses (Digitaltransactions, October 2009).

The introduction of online funds transfers opens up new payment opportunities. Many discussions are taking place these days concerning where mobile banking is heading. At this stage, mobile banking in the United States does not offer much beyond a tiny Web interface that

allows depositors to view their balances on their cellular phones. Section 2 reports on some 
recent developments in "true" mobile banking, which involves the transfer of funds from one bank account to another (see also McGuire and Crowe 2009). The ACH and the EFT (electronic funds transfer) seem to be the least costly ways of implementing "mobile" transfers of funds. For example, a depositor could send an encrypted short message (SMS) to the bank, asking the bank to originate an $\mathrm{ACH}$ credit entry to another bank account. Finally, as discussed in Section 8.3, 10 years down the road, we may be able to use $\mathrm{ACH}$ networks that connect directly to businesses and possibly bypass the need to go through banks. 


\section{Appendix A. Overview of ACH Networks in the United States}

Because most of P2P funds transfers between banks clear through automated clearing houses, it is important to understand how these networks actually work. The Fed and the Electronic Payments Network (EPN, www.epaynetwork.com) operate the $\mathrm{ACH}$ network (automated clearing house). Transfers on these networks include direct deposit payroll, vendor payments, consumer electronic bill payments, such as insurance, mortgages, and utilities, social security and other government benefits, tax refunds, and check conversions. Some large online retailers, such as Amazon, are also increasingly using $\mathrm{ACH}$ as a substitute for online use of the more costly credit or debit cards. Buyers can simply input their routing and account numbers instead of card numbers. The Internal Revenue Service also uses the $\mathrm{ACH}$, whereby taxpayers can receive refunds in matter of days (or pay their taxes electronically, if they owe). Table 2 provides some information about the volume of $\mathrm{ACH}$ transactions. ${ }^{23}$

\begin{tabular}{l|lll} 
Year & 2006 & 2007 & 2008 \\
\hline Commercial via Network & 11.32 & 12.93 & 13.81 \\
& & $13.9 \%$ & $7.1 \%$ \\
Commercial Off Network & 2.78 & 3.13 & 3.32 \\
& & $12.5 \%$ & $6.1 \%$ \\
Government & \multirow{2}{*}{1.00} & 1.04 & \\
& & $3.6 \%$ & 1.14 \\
Total via Network & 12.32 & 13.97 & $10.2 \%$ \\
& & $13.4 \%$ & 7.96 \\
Total & 15.10 & 17.10 & 18.28 \\
& & $13.2 \%$ & $6.9 \%$ \\
\hline
\end{tabular}

\section{Table 2: ACH transaction volume (billions).}

Source: NACHA. Note: percents indicate change from previous year.

\footnotetext{
${ }^{23}$ Check volume in 2006 was 30.6 billion transactions, according to the 2007 Federal Reserve Payments Study. See Gerdes (2008).
} 
Because P2P transfers are just at the beginning stage in the United States, commercial transactions in Table 2 include almost entirely P2B, B2P, and B2B transactions, such as bill payments. If adoption of $\mathrm{P} 2 \mathrm{P}$ via $\mathrm{ACH}$ exceeds its critical mass, it will be useful to separate P2P transaction data from $\mathrm{P} 2 \mathrm{~B}$ and $\mathrm{B} 2 \mathrm{~B}$. Also, notice that Table 2 provides data on off-network transactions, which is an important category because it includes "on-us" transactions (transactions that clear within the same or contracting financial institutions). As mentioned earlier, large banks have already cut some costs by clearing P2P transactions internally and in real time without using the $\mathrm{ACH}$ network.

Bradford (2007) summarizes the history of the ACH network in the United States as well as some current and future developments. The $\mathrm{ACH}$ Network is a nationwide, batch-oriented, electronic funds transfer system that provides for the interbank clearing of electronic payments by participating depository financial institutions. The Federal Reserve and the EPN act as ACH central clearing facilities through which financial institutions transmit and receive $\mathrm{ACH}$ entries. $\mathrm{ACH}$ is governed by the rules of the National Automated Clearing House Association (NACHA), www.nacha.org.

A simple way of looking at an $\mathrm{ACH}$ transaction is to view it as a sequence of two email messages. The first is sent from one bank (or, more generally, one financial institution) to the $\mathrm{ACH}$ operator, and a second message is sent from the $\mathrm{ACH}$ operator to another financial institution. The bank that sends the first message is called the "originating depository financial institution" (ODFI). The bank that receives the second message is called the "receiving depository financial institution" (RDFI). 
Figure 8 below illustrates how Oscar (originator) and Rachel (receiver) can transact via the $\mathrm{ACH}$ network, assuming that Oscar handles his transactions via a Bank called OB (for "originating bank") and Rachel via a bank called RB (for "receiving bank").

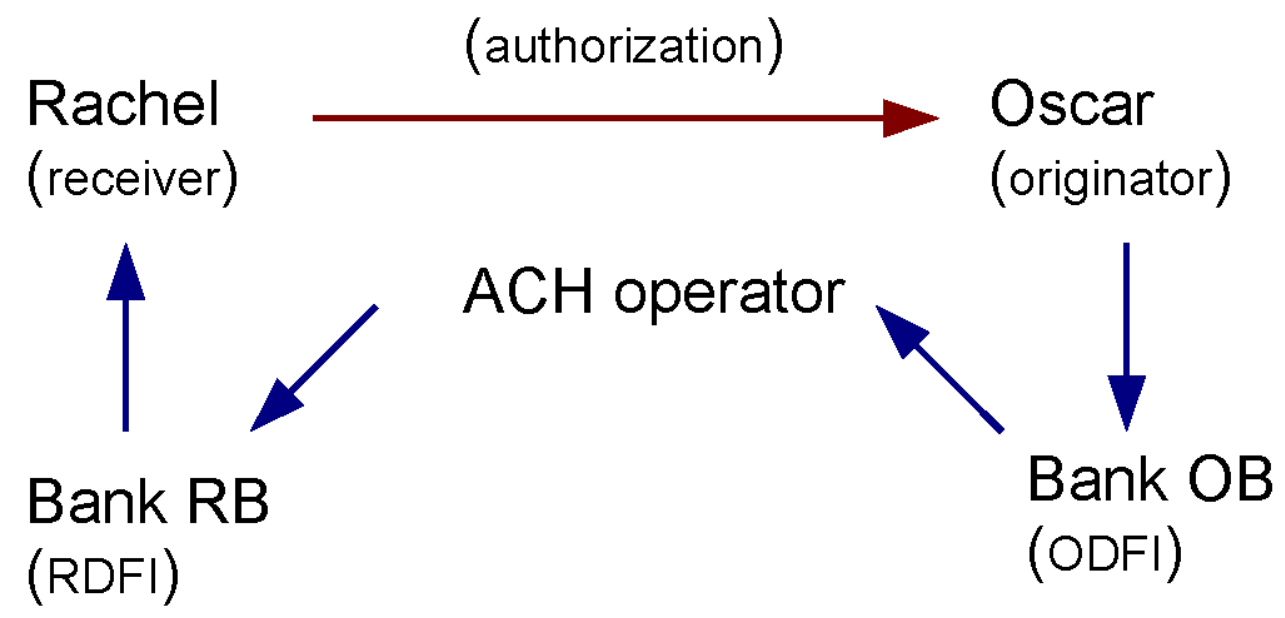

Figure 8: An illustration of P2P funds transfer via ACH.

Any $\mathrm{ACH}$ transaction in general and $\mathrm{P} 2 \mathrm{P}$ in particular must follow the following five stages:

1. Rachel (receiver) authorizes Oscar (originator) to credit or debit her account. She provides Oscar with her bank account and routing numbers (also known as the American Banking Association or ABA number).

2. Oscar requests Bank OB to credit or debit Rachel's personal bank account with Bank RB.

3. Bank $\mathrm{OB}$ adds Oscar's request to other $\mathrm{ACH}$ requests and sends a batch file to an $\mathrm{ACH}$ operator.

4. The ACH operator sends a request to Bank RB to credit or debit Rachel's account.

5. Bank RB credits or debits Rachel's bank account. 
At this stage, the $\mathrm{ACH}$ operator settles the transaction between bank $\mathrm{OB}$ and bank RB. Note that the term "receiver" does not necessarily mean that the receiver receives money. Receiver simply refers to the party who does not initiate the $\mathrm{ACH}$ debit or credit entry. Finally, although Figure 8 illustrates a $\mathrm{P} 2 \mathrm{P}$ transfer, any other $\mathrm{ACH}$ transfer such as $\mathrm{B} 2 \mathrm{P}$ and $\mathrm{P} 2 \mathrm{~B}$ follows exactly the same steps.

The above description indicates that the originator of a credit or a debit ACH entry must obtain an "authorization" from the receiver. A natural question that comes up at this stage is whether the slow adoption of $\mathrm{P} 2 \mathrm{P}$ via the $\mathrm{ACH}$ in the United States can be attributed to stricter authorization rules than exist in other countries. As it turns out, this is not the case.

Current NACHA rules require the originator (Oscar in the above example) to obtain an authorization from the receiver (Rachel) prior to initiating any $\mathrm{ACH}$ credit or debit entry. NACHA (2008, p.15) rules state as follows:

A written agreement with the originating company signed or similarly authenticated by an employee or customer to allow payments processed through the ACH network to be deposited in or withdrawn from his or her account at a financial institution...For ACH credit entries, authorization may also be by verbal or other non-written means.

Thus, the above quotation makes it clear that NACHA rules do not impose any obstacle to P2P (or any account-to-account) credit transfers, because even a verbal authorization is sufficient to initiate an $\mathrm{ACH}$ credit entry. All that is needed for a P2P platform is the incorporation of mechanisms whereby a recipient of an unwanted credit transfer can reject or return it to the originator. Indeed, some P2P providers described in Section 2 do incorporate such safety protocols, whereby the receipient receives an email or an SMS message asking for confirmation that the recipient indeed wants to be credited. Regardless, unwanted credit transfers are unlikely to be realized very often. From the technical point of view, banks are already capable of blocking unwanted credit or debit entries, although consumers may be unaware of these technical details. 


\section{Appendix B. P2P Electronic Transfers in Europe}

Section 4 provided some data on the widespread use of $\mathrm{ACH}$ transfers in many European countries. In some of these countries, account holders lack checkbooks, so P2P transfers are accomplished only via ACH operators or "on-us" agreements among banks. The widespread use of noncheck transfers in Europe can be attributed to the adoption of the Giro network via post offices in most European countries by the middle of the 20th century. Commercial banks were linked to the national Giro network so depositors were able to pay their bills or transfer money either by going to the nearest post office or by visiting their bank's local branch. Over time, European banks joined national ACH networks for transferring money among banks within the same country. With the introduction of the Internet and online banking, consumers and businesses instantaneously adapted and started making online P2P, B2P, and P2B transfers.

In the United States, the transition to online funds transfers has taken much longer, because households did not have access to such Giro systems at least until 1983, when some households started using "direct debits" for automatic deduction of bill payments. However, all P2P transfers were still based on cash and paper check writing. Still, one may wonder why the transition from the Giro system to online funds transfer has been faster in Europe than the transition from paper checks to online transfers in the United States. One possible explanation is that the Giro system is "push"-based technology that is similar to P2P transfers, which are also "push"-based, since both are initiated by the payer. In contrast, a check payment is "pull"based, since it is initiated by the payee, who must instruct her own bank to debit the payer's account in another bank. The point is that there is a big difference in the roles played by payers and payees in the transfer process and this characteristic distinguishes the American (pullbased) check writing habit from the process in the European countries that relied on the (pushbased) Giro network.

Turning again to Europe, with the adoption of the Euro as a single currency, the European Central Bank (ECB) initiated and supported projects for the purpose of enabling low-cost electronic funds transfers throughout Europe. The ECB has established TARGET2 (Trans- 
European Automated Real-time Gross Settlement Express Transfer System). Before TARGET2, most cross-border transfers used SWIFT (the Society for Worldwide Interbank Financial Telecommunication, founded in 1973, with headquarters in Belgium), which operates a worldwide financial messaging network that exchanges messages between banks and other financial institutions (see www.swift.com). TARGET2 was designed for making large crossborder euro payments in real time and hence was not suitable for low-value P2P transfers.

In 2002, the European Central Bank adopted the SEPA project (Single Euro Payments Area), which allows customers to make noncash euro payments to any beneficiary located anywhere in the euro area, using a single bank account and a single set of payment instruments. The progress of SEPA is discussed in Chaplin (2008). The European system generally assigns a unique routing number (International Bank Account Number, or IBAN) to every bank account (individual or business). Credit transfers based on the IBAN are widely used in some European countries even for very small transactions. Some attempts are being made to integrate SEPA with non-European networks such as FedACH FedGlobal services. It should be pointed out that SEPA uses slightly different terminology from that used in the United States, for example, "originator" is called "debtor" whereas "ODFI" is called "debtor agent" (a debtor agent need not even be a bank in Europe).

Another objective of SEPA is to enable the emergence of direct debit cards that use the same clearing network as electronic funds transfers. The Payment Services Directive (PSD), which all European markets must pass into national law, attempts to maintain the same legal framework for direct debit cards as for electronic funds transfers. Brand-name card associations will have to adapt to the new directive. It will be interesting to see whether similar ACH debit cards will develop in the United States. 


\section{References}

Adams, R., P. Bauer and R. Sickles. 2004. "Scale Economies, Scope Economies, and Technical Change in Federal Reserve Payment Processing." Journal of Money, Credit and Banking. 36(4): 943-958.

Bergman, M., G. Guibourg, and B. Segendorf. 2007. "The Costs of Paying - Private and Social Costs of Cash and Card Payments." Bank of Sweden. Working Paper No. 212.

Bradford, T. 2001. "The P-2-P Payments Proposition." Federal Reserve Bank of Kansas City, Newsletter Article. Spring.

Bradford, T. 2007. “The Evolution of the ACH." Federal Reserve Bank of Kansas City, Payments System Research Briefing. December.

Chakravorti, S. 2000. "Why Has Stored Value Not Caught On?" Emerging Issues Series, S\&R2000-6. Federal Reserve Bank of Chicago.

Chaplin, J. 2008. “Single Euro Payments Area: Is Europe’s Card Business Making the Major Changes that were Widely Predicted Or is the Whole Initiative Going Flat?" Journal of Payments Strategy \& Systems. 3: 17-23.

Connolly, P. 2007. "Transformation of the Check System: The ACH Example." Speech to the Bankers Forum, Hartford, Connecticut.

D'Silva, V. 2009. "Payments in Flux: Megatrends Reshape the Industry." In: R. Litan and M. Baily (eds.) Moving Money: The Future of Consumer Payments. Washington D.C.: Brooking Institution Press.

Economides, N., and C. Himmelberg. 1995. "Critical Mass and Network Size with Application to the US Fax Market." NYU Stern School of Business Discussion Paper No. EC-95-11.

Foster, K., E. Meijer, S. Schuh, and M. Zabek. 2009. "The 2008 Survey of Consumer Payment Choice." Federal Reserve Bank of Boston, Public Policy Discussion Paper No. 09-10.

Gerdes, G. 2008. "Recent Payment Trends in the United States." Board of Governors, Federal Reserve Bulletin. October: A75-A106.

Gowrisankaran, G., and J. Stavins. 2004. "Network Externalities and Technology Adoption: Lessons from Electronic Payments." RAND Journal of Economics. 35: 260-276.

Gresvik, O., and H. Haare. 2009. "Costs in the Norwegian Payment System.” Bank of Norway, Payment Systems Department, Staff Memo No. 4/2009. 
Humphrey, D., L. Pully, and J. Vesala. 2000. "The Check's in the Mail: Why the United States Lags in the Adoption of Cost-Saving Electronic Payments." Journal of Financial Services Research, 17(1): 17-39.

Humphrey, D., M. Kim, and B.Vale. 2001. "Realizing the Gains from Electronic Payments: Costs, Pricing, and Payment Choice." Journal of Money, Credit and Banking. 33(2): 216-234.

Humphrey, D., Willesson, M., Lindblomand, T, and Bergendahl, G. 2003. “What Does it Cost to Make a Payment?" Review of Network Economics, 2: 159-174.

Javelin Research \& Strategy. 2009. Multi-Channel Account-to-Account Transfers andP2P Payments Forecast: Evaluating Trends and Assessing the Future 2006-2014.

Knorr, M. 2008. "Payment Systems Convergence." Journal of Payments Strategy E Systems. 3: 616.

Kuttner, K., and J. McAndrews. 2001. “Personal On-Line Payments.” Federal Reserve Bank of New York, Economic Policy. 7: 35-50.

Lacker, J., and J. Weinberg. 1998. “Can the Fed be a Payment System Innovator?" Federal Reserve Bank of Richmond, Economic Quarterly. Spring: 1-25.

Lacker, J., J. Walker, and J. Weinberg. 1999. “The Fed's Entry into Check Clearing Reconsidered." Federal Reserve Bank of Richmond, Economic Quarterly. Spr: 1-32.

Litan, R., and M. Baily. 2009. "Introduction." In: R. Litan and M. Baily (eds.) Moving Money: The Future of Consumer Payments. Washington D.C.: Brooking Institution Press.

McGuire, B., and M. Crowe. 2009. "Mobile Banking in New England: The Current State of the Market." Banking PayPers: Updates on Payment Trends from the Federal Reserve Bank of Boston. August.

NACHA. 2008. "ACH Rules: A Complete Guide to Rules \& Regulations Governing the ACH Network."

Nelson, P. 1970. "Information and Consumer Behavior." Journal of Political Economy. 78(2): 311329.

Rohlfs, J. 1974. “A Theory of Interdependent Demand for a Communications Service.” Bell Journal of Economics and Management Science. 5: 16-37.

Roth, J. 2008. “Expedited Payments: A Fee Service to Compensate for Rising Costs of Online Bill Payments." Journal of Payments Strategy \& Systems. 3: 24-33. 
Rysman, M. 2009. "The Economics of Two-Sided Markets." Journal of Economic Perspectives. 23(3): 125-143.

Schreft, S. 2007. "Risks of Identity Theft: Can the Market Protect the Payment System?" Federal Reserve Bank of Kansas City, Economic Review. Fourth Quarter.

Shy, O. 2001. The Economics of Network Industries. Cambridge: Cambridge University Press.

Shy, O. 2008. How to Price. Cambridge: Cambridge University Press.

Shy, O., and J. Tarkka. 2002. "The Market for Electronic Cash Cards." Journal of Money, Credit, $\mathcal{E}$ Banking. 34: 299-314.

Schuh, S., and J. Stavins. Forthcoming. "Why Are (Some) Consumers (Finally) Writing Fewer Checks? The Role of Payment Characteristics." Journal of Banking and Finance.

Stavins, J. 1997. "A Comparison of Social Costs and Benefits of Paper Check Presentment and ECP with Truncation," Federal Reserve Bank of Boston, New England Economic Review. July/August: 27- 44 .

VanHoose, D. 2009. "Internet Banking." Networks Financial Institute, Policy Brief No. 2009-PB12.

Van Hove, L. 2001-2. "The New York City Smart Card Trial in Perspective: A Research Note." International Journal of Electronic Commerce. 5(2): 119-131.

Weiner, S. 2008. “The Federal Reserve's Role in Retail Payments: Adapting to a New Environment." Federal Reserve Bank of Kansas City, Economic Review. Fourth Quarter.

Wells, K. 1996. "Are Checks Overused?" Federal Reserve Bank of Minneapolis, Quarterly Review. 20(4): 2-12. 